\title{
The history of pediatrics at Baylor University Medical Center
}

\author{
Percy E. LueCKE, JR., MD
}

I

$\mathrm{n}$ the long annals of medical history, pediatrics is a young specialty, scarcely 200 years old. Medical writings from antiquity did include diseases in children but only in conjunction with general topics. A few examples follow:

- The Ebers Papyrus, written about $1552 \mathrm{BC}$ and unearthed in 1872, discussed, among other topics, breastfeeding, a cure for worms, and treatment of eye diseases.

- Writings of Hippocrates (c. 400 BC) covered cephalhematoma, hydrocephalus, clubfoot, worms, diarrhea, scrofula, asthma, and mumps.

- Soranus of Ephesus (c. AD 100) described the fingernail test for breast milk quality. (If the droplet clings to the nail, it contains sufficient fat. If not, it is watery.)

- Galen (c. AD 200) wrote of ear discharge, pneumonia, and intestinal prolapse and described a disorder that corresponds to rickets.

- Avicenna, the great Arabian physician (c. AD 990), discussed tetanus, worms, convulsions, meningitis, and umbilical abscess.

- Avenzoor (c. 1150) performed a tracheotomy on a goat.

- Hieronymus wrote the first important printed book about children in 1583, entitled De Morbus Pusiorum.

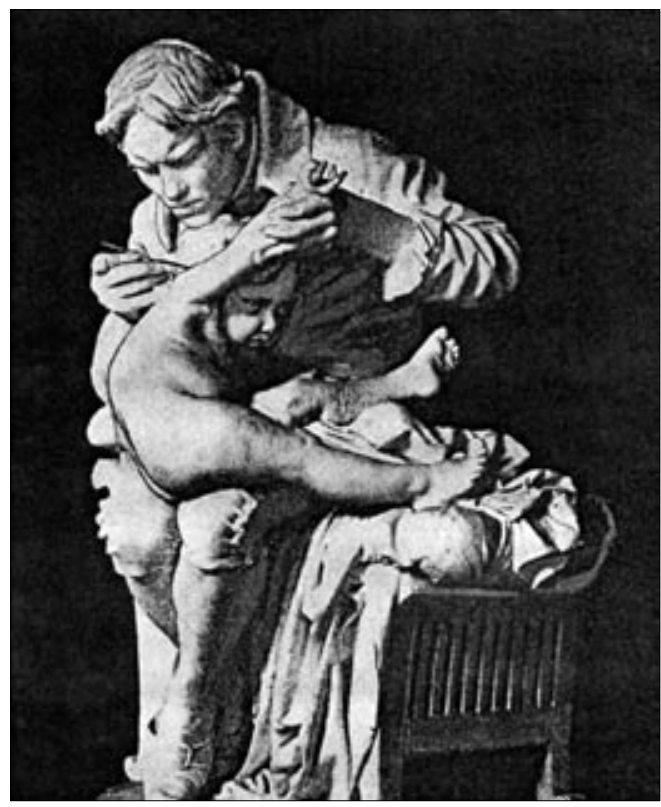

Figure 1. Jenner Vaccinating a Child by Giulio Monteverdi, Genoa. Reprinted from reference 3.
Among the increasing number of authors who wrote about diseases in children during the 17 th and 18 th centuries, 2 deserve mention. Thomas Sydenham (1624-1689), the English Hippocrates, wrote on scarlet fever, measles, smallpox, epilepsy, rickets, teething fever, scorbutus (scurvy), and the chorea we know as St. Vitus Dance. Edward Jenner (1749-1823) inoculated an 8year-old boy with cowpox matter into one arm and 6 weeks later inoculated smallpox matter into the other arm (Figure 1). The boy did not get smallpox, heralding

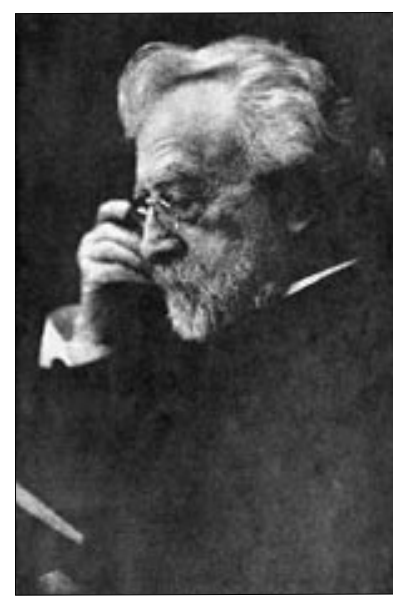

Figure 2. Dr. Abraham Jacobi (18301919). Reprinted from reference 1. one of the greatest medical benefits of all time: the prevention of disease by immunization (1).

By the late 1700 s and early 1800 s, the need to attend specifically to the care, development, and diseases of children became more apparent, and specialization in pediatrics evolved, particularly in Germany and France. An early, if not the first, specialty organization was the Society for Infant Therapeutics, formed in Germany in 1883 (2).

\section{PEDIATRICS IN THE USA}

Although other American physicians were writing about children's diseases, the father of American pediatrics is considered to be Dr. Abraham Jacobi (1830-1919) (Figure 2), a German pediatrician, who arrived in New York in 1853 and established the pediatrics chair at the New York Medical College in 1861, organized several pediatric societies, began publication of several pediatric journals, and developed children's departments in several New York hospitals (3). A prolific writer, he taught extensively about the feeding and hygiene of children (including

From the Department of Pediatrics, Baylor University Medical Center, Dallas, Texas.

Historical articles published in Proceedings will be reprinted in How We Care, volume 2. Readers who have any additional information, artifacts, photographs, or documents related to the historical articles are asked to forward such information to the Proceedings' editorial office for possible inclusion in the book version.

Corresponding author: Percy E. Luecke, Jr., MD, 6832 Meadow Lake Avenue, Dallas, Texas 75214. 


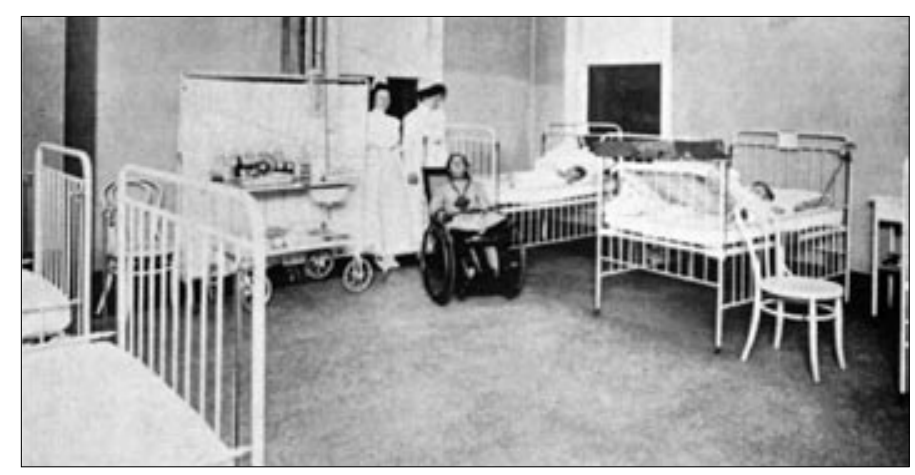

Figure 3. A special ward for children in the Texas Baptist Memorial Sanitarium.

repeated warnings of the fallacy and danger of washing the infant's mouth - a practice that was condemned as early as 1544 in the writings of Feliz Würz but is still practiced by some today). Along with Jacobi, pioneers such as Luther Emmett Holt in New York, J. Forsyth Meigs in Philadelphia, and William McKim Marriott in St. Louis rapidly expanded the specialty through their writings and teachings. The first separate pediatrics hospital was founded in Philadelphia in 1855. The American Academy of Pediatrics was established in 1930 and the American Board of Pediatrics in 1933.

\section{PEDIATRICS IN DALLAS}

Pediatrics as a distinct specialty in Dallas began with the arrival in 1908 of Dr. Hugh Leslie Moore. Dr. Moore had begun a general practice in Van Alstyne, Texas, but his interest in pediatrics led him to England and Germany to study the new specialty. Upon his return, he settled in Dallas as the first pediatrician in the state of Texas and joined the staff of the Texas Baptist Memorial Sanitarium (4). Tireless in his efforts to meet the needs of children, he was the dominant force in pediatrics in Dallas over 4 decades. Not only was he head of pediatrics at Baylor until 1947, but he was also head of pediatrics at the Bradford Hospital, established in 1929, and Texas Children's Hospital and Freeman Clinic in the 1940s. In addition to his private practice, he was chief of pediatrics of the Baylor University College of Medicine before it relocated to Houston in 1943. Generous to his fellow physicians, he would provide free office space to new pediatricians until their practices were established. His grandson and namesake, Dr. Hugh Leslie Moore II, also a pediatrician, remembers him as a gentle and distinguished man who, with his wife, often joined them for Sunday dinner and who was fond of golf.

During the first 5 decades of the 1900s, various child care activities and facilities evolved, which are briefly summarized below.

- April 1913: A "baby camp" was set up in tents on the lawn of the city-county Parkland Hospital built at Maple and Oak Lawn Avenues. The initial principal purpose for the camp was to treat infants with summer diarrhea by injecting saline solutions subcutaneously or into the abdominal cavity. The camp later acquired a cottage on Oak Lawn Avenue.

- September 1921: A free clinic was opened in the basement of the First Presbyterian Church at Harwood and Wood Streets. It was organized by the Rev. William Anderson and Dr. Jack Perkins and functioned with volunteer physicians and nurses who donated time and services.
- Spring 1924: The Presbyterian Clinic opened in a new building at Maple and Welborn Streets. In 1932, it was named the Richmond Freeman Memorial Clinic.

- January 1930: The Bradford Memorial Hospital for Babies incorporated the baby camps and opened at the corner of Maple and Oak Lawn Avenues.

- July 1937: Dr. Floyd Norman was named the first full-time resident of the Freeman Clinic.

- July 1938: Dr. Stephen Halcuit Moore became the second paid resident at Freeman Clinic.

- July 1939: Ground was broken for the Texas Children's Hospital adjacent to the Freeman Clinic. The first patient was admitted on September 13, 1940.

- January 1940: The Bradford and Freeman boards agreed to hire a full-time resident. Dr. Gladys Fashena was named director of the Freeman Clinic. Dr. Salmon R. Halpern was hired in August as chief resident for the three units.

- January 1941: The Texas Children's Hospital's name was changed to the Children's Hospital of Texas to avoid confusion with a facility in Houston.

- 1943: Children's Hospital set up a teaching relationship with the Baylor School of Nursing.

- February 1948: The Bradford, Children's, and Freeman hospitals were combined under one charter as the Children's Medical Center.

- December 1951: The Ivor O'Connor Morgan Hospital for Tuberculous Children opened adjacent to the Children's Hospital.

- October 1954: Dr. Edward L. Pratt, who had succeeded Dr. Gladys Fashena as professor of pediatrics at Southwestern Medical School, became chief of staff of the hospitals.

- July 1967: The new Children's Medical Center of Dallas opened adjacent to Parkland and the medical school on Harry Hines Boulevard.

- July 1996: The Columbia Children's Hospital at Medical City Dallas was founded (5).

\section{PEDIATRICS AT BAYLOR}

During the first 2 decades of the 1900s, most children were cared for by general practitioners. After World War I and during the 1920s and 1930s, pediatricians began arriving from the various centers. Most of them were on the staffs of all the major hospitals—Baylor, St. Paul, Parkland, and Methodist—but among those that were more closely associated with Baylor were Drs. Jack Perkins, Gordon McFarland, Ramsey Moore, Harold Nesbit, John Young, Percy E. Luecke, Sr., John Dunlap, Floyd Norman, S. Halcuit Moore, and H. L. Moore's son, Robert L. Moore. In 1938, there were 12 pediatricians in Dallas, and by 1958, there were 24 pediatricians on the Baylor staff (6).

\section{Facilities}

Children have always been cared for on the Baylor site, beginning with the opening by Dr. Charles Rosser of the Good Samaritan Hospital in 1901, the second private general hospital in Dallas after St. Paul Hospital. It was purchased by the Baptist General Convention of Texas and dedicated as the Texas Baptist Memorial Sanitarium in March 1904 and then enlarged and reopened in October 1909 (Figure 3). One of the early patients 

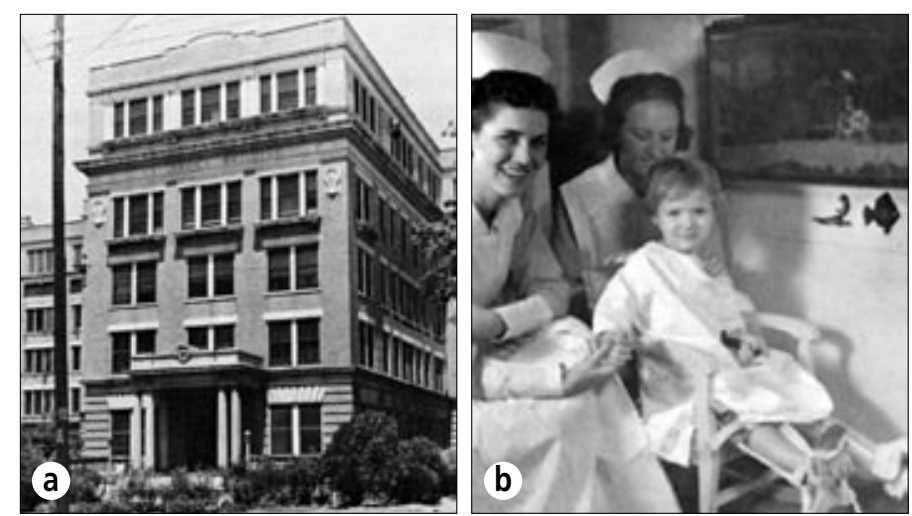

Figure 4. (a) The Children's Building, 1922. (b) Nurses care for a young patient in the Children's Building, 1928.

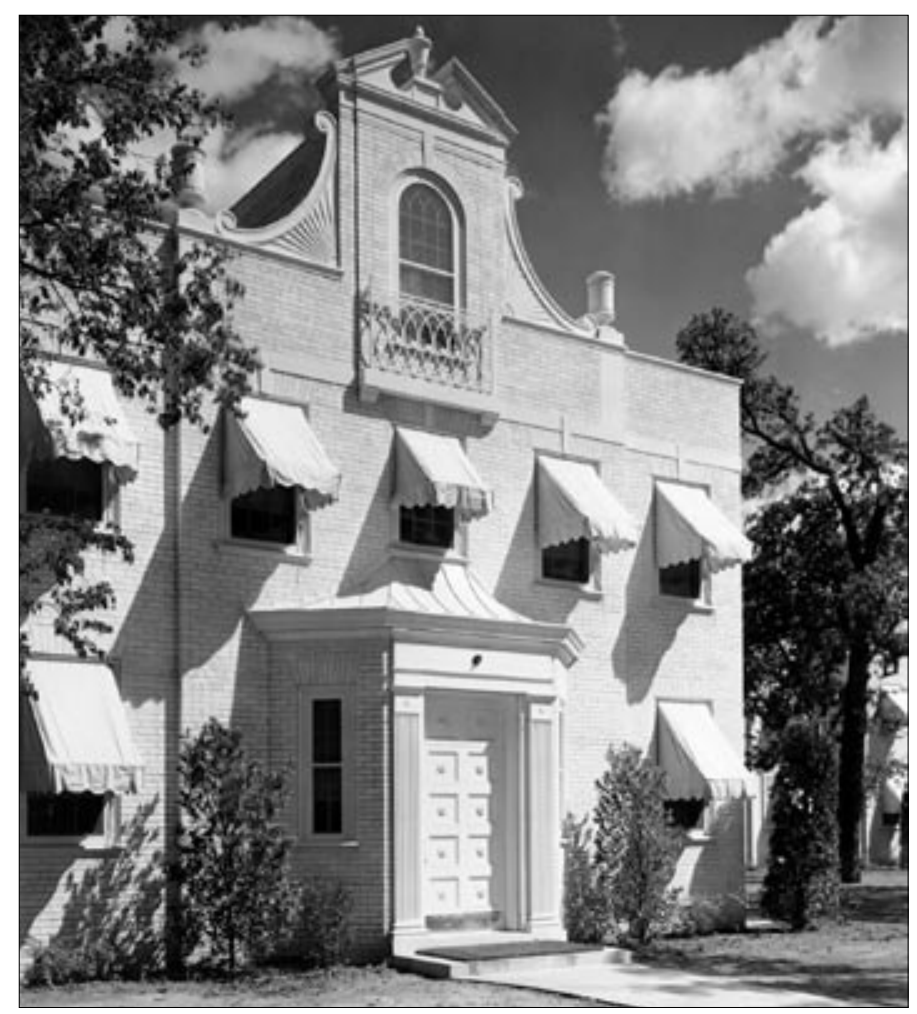

Figure 5. Florence Nightingale Hospital, 1937.

was 11-year-old Edyth Brown (later Mrs. Joe Harrell), who later wrote an account of her stay and of being visited by Dr. George Truett (4). Facilities were expanded by the 5 -story Children's Building in 1922 (Figure 4), which greatly increased the capacities of pediatrics, gynecology, and obstetrics.

It was in the Weinberger Laboratory, named after the founder of Word Drug Company, and in the Wadley Blood Center that Dr. Sol Haberman and Dr. Joseph Hill did some of the pioneering work in the discovery and elucidation of the Rh (CDE) blood factor. In pediatrics, erythroblastosis fetalis, a condition causing antepartum or early postpartum death or severe brain-damaging jaundice is the result of an Rh-negative mother developing hemolyzing antibodies against her fetus' Rh-positive blood. Exchange transfusion by which the infant's Rh-positive blood is sequentially replaced with donor Rh-negative blood was developed. Because some Baylor staff physicians were skilled in this technique, Baylor became one of the area centers for the procedure.

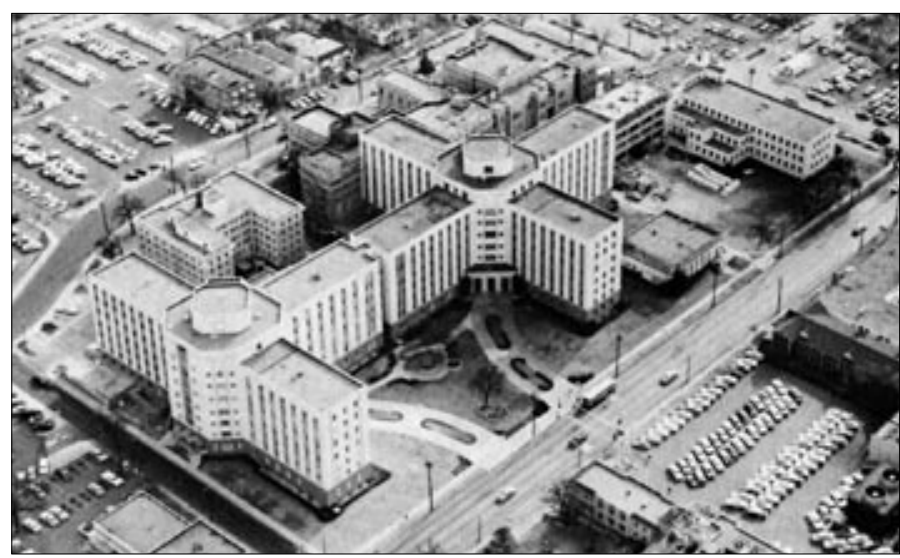

Figure 6. The 3-winged unit of the Women and Children's Hospital (later, Hoblitzelle Hospital) on the left, adjoining the 4-winged Truett Memorial Hospital, 1959.

Pediatrics and gynecology remained in the Children's Building after obstetrics moved in 1937 to the new Florence Nightingale Maternity Hospital, which was acclaimed the "last word" in maternity and newborn care at the time (Figure 5). The popularity of the hospital resulted in an increase in deliveries from 1055 in 1937 to 6800 in the early 1950s. By then, however, the hospital had become totally inadequate, and a fundraising campaign was begun for a new women and children's hospital. In 1958, maternity services were moved back to the Veal Teaching and Research Hospital — the old Texas Baptist Memorial Sanitarium renamed for Minnie S. Veal, the daughter of Col. C. C. Slaughter. The old Nightingale Hospital was torn down to make way for a new building.

On October 28, 1959, the new Women and Children's hospital was dedicated (Figure 6). It contained 120 maternity beds and 150 newborn bassinets. It consisted of 3 newborn nurseries, 2 isolation nurseries, and 1 premature nursery. The pediatric section consisted of a 44-bed wing on the sixth floor and a separate 21-bed wing on the seventh floor for teenaged patients 12 to 20 years of age. This latter floor was named "the 12-to-20 club" and was established in recognition of the emerging subspecialty of ephebiatrics, or adolescent medicine. The hospital was later renamed the Karl and Esther Hoblitzelle Hospital after generous donors (4). Other hospitals—St. Paul, Methodist, and Parkland—also had pediatric inpatient floors, but none matched the scope and quality of those at Baylor. Other pediatric hospitals at that time in Dallas were the Bradford Hospital, established in 1929, and the Texas Children's-Freeman Clinic-Ivor O'Connor complex of the 1930s and 1940s, each with its own governing board.

In the early 1960s, the need to coordinate pediatric care and to establish closer relations with the medical school led to a successful fundraising campaign and the opening of the Children's Medical Center adjacent to Parkland Hospital in July 1967. The new hospital, plus an increase in day surgery and in office procedures, led to a gradual decline in the need for the usual inpatient services at Baylor-particularly in otolaryngology, pediatric surgery, plastic surgery, and urology — during the 1970s and 1980s.

\section{Efforts for subspecialization}

In the mid 1980s, there was a perceived desirability to develop subspecialty services within the pediatric department, both for inpatient care and for outpatient consultation. Pediatric ortho- 


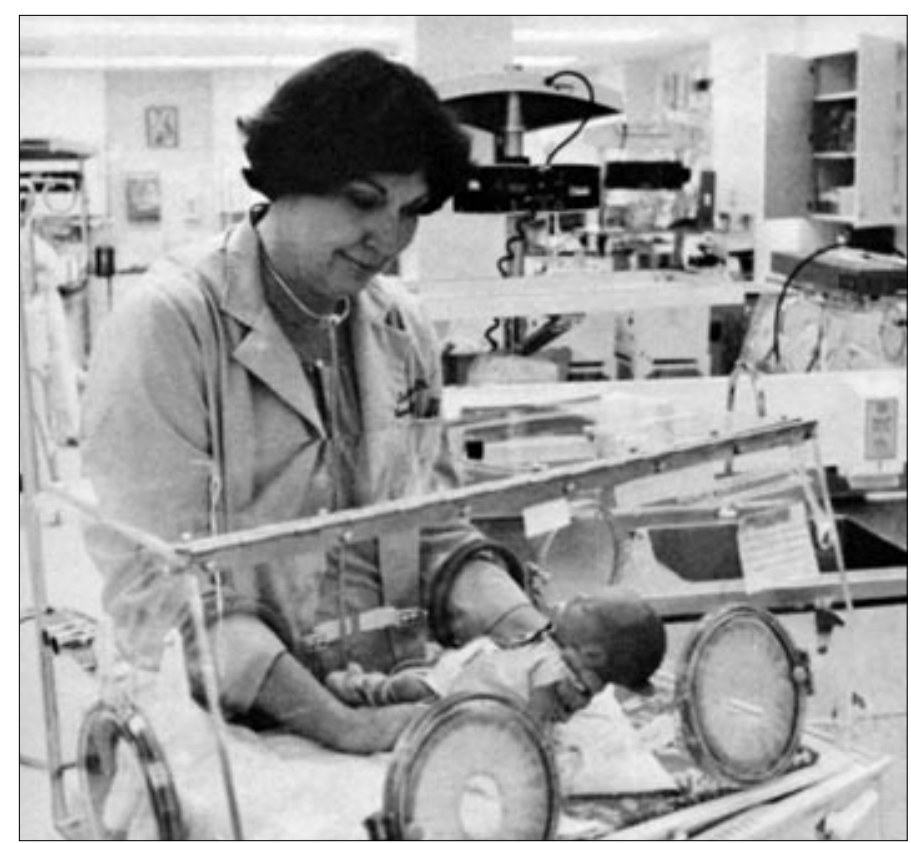

Figure 7. Dr. Dolores Carruth in the Blanche Swanzy Lange Special Care Nursery.

paedics, largely under Dr. Wynne Snoots, and pediatric surgery under Dr. Dale Coln were provided with more operating, recovery, and intermediate intensive care rooms. Dr. Richard L. Wasserman joined the staff for allergy and immunology. Dr. Ronald Hogg was added for pediatric nephrology. A department of metabolic and genetic disorders was created.

While the pediatric subspecialties did well into the 1990s, they never reached the potential originally envisioned for them and-except for pediatric surgery-were discontinued in the latter 1990s. The need for inpatient care continued to decline, and in April 2002, patients were referred to Children's Medical Center of Dallas. A 4-bed pediatric unit remains for pediatric surgical cases and the occasional medical patient.

\section{Baylor neonatal intensive care unit}

In the 1960s and 1970s, developments in technology and procedures were resulting in vast improvements in the care of premature and sick newborns. In response to these developments and to the Baylor obstetric department's competence as a highrisk facility, Dr. Dolores Carruth, a neonatologist at Southwestern Medical School, was named a consultant in 1968 and became the full-time director of nurseries in 1973 (Figure 7). A "special care unit" was developed with the generous help of Ross Laboratories and-along with Children's Medical Center-became the only specialized newborn care center in the Dallas area (4). Later, Methodist Hospital in Dallas and John Peter Smith Hospital in Fort Worth developed similar units. These four facilities provided referral services and outreach programs for the entire North Texas area. Drs. Shirley Kindberg and Rudolph Barta later joined Dr. Carruth as the unit grew in both size and scope of services. Ultrasonography, oximetry, microchemistry techniques, parenteral nutrition, and the use of surfactant to aid lung expansion (Baylor was one of the nationwide test sites for this) led to marked outcome improvements.

In 1991, Dr. Jonathan Whitfield was recruited to become director of neonatology and nurseries. He came from The Children's
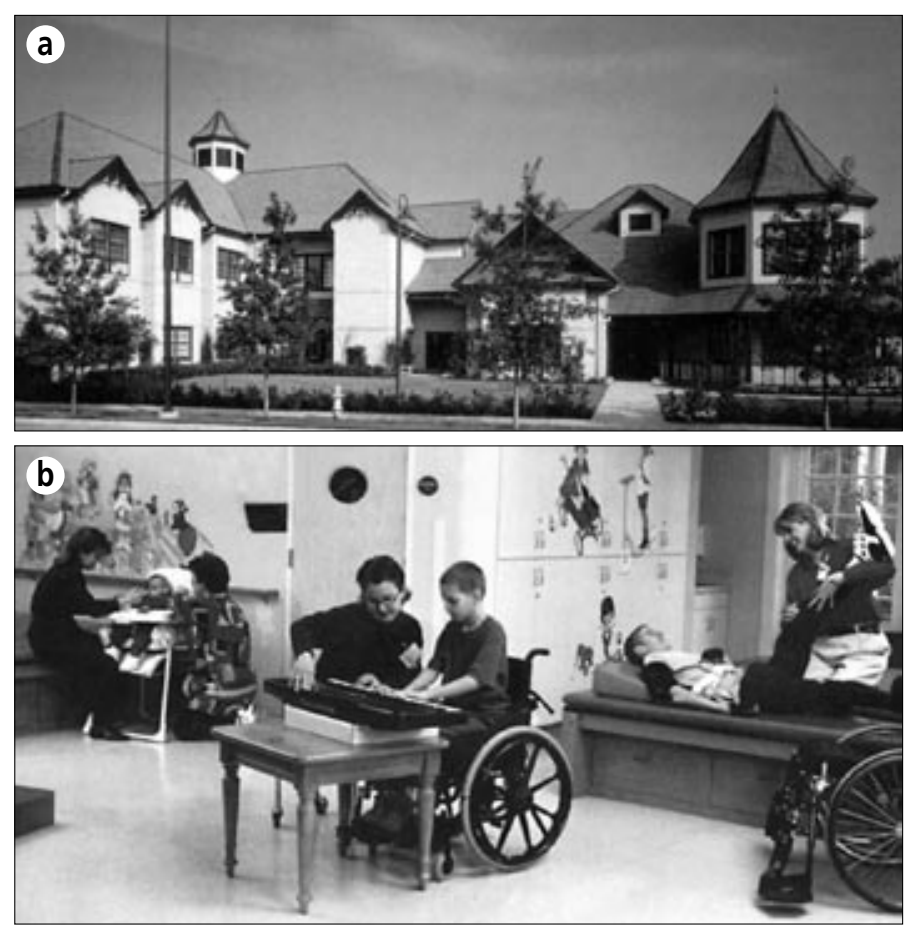

Figure 8. Our Children's House at Baylor: (a) the exterior; (b) a rehabilitation room.

Hospital in Denver, Colorado, where he had been on staff since 1978. Under Dr. Whitfield's direction, the service has continued to grow in both size and reputation and currently consists of 37 intensive, 35 intermediate, and 40 general nursery beds.

Follow-up care is provided by the TINY TOTS Clinic (The

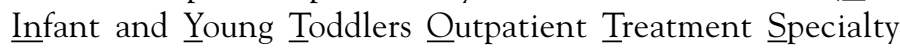
Clinic) for "graduates" of Baylor's neonatal intensive care unit and by Baylor's Our Children's House.

\section{Our Children's House}

During the tenure and through the efforts of Dr. Robert Kramer, a new dimension in Baylor's care for children began in December 1993 after a 3-year period of planning and fundraising. The Baylor Center for Restorative Care, in a beautiful freestanding building at Swiss Avenue and Hall Street, originally began as a pediatric rehabilitation center providing care and parent instruction for disabled and chronically ill children. However, the volume and scope of services steadily expanded to include inpatient acute and subacute care for trauma and severe medical illnesses, transitional care to prepare for life at home, and ventilatory and palliative care. To reflect this change, the name Our Children's House was adopted (Figure 8). Outpatient services include evaluation, education, and treatment for trauma and for developmental, congenital, speech-language, and sensory disorders. These services are provided by physicians, nurses, respiratory therapists, occupational therapists, physical therapists, speech therapists, dietitians, teachers, and case managers. In addition to the original Our Children's House, there are satellite facilities in Allen, Coppell, Irving, and Waxahachie.

\section{Chiefs of service}

Over the past $9+$ decades, 7 pediatricians have served as chief: Dr. Hugh Leslie Moore, 1908 to 1947; Dr. Robert L. Moore (H. L. Moore's son), 1947 to 1968; Dr. Floyd Norman, 1968 to 1970; 

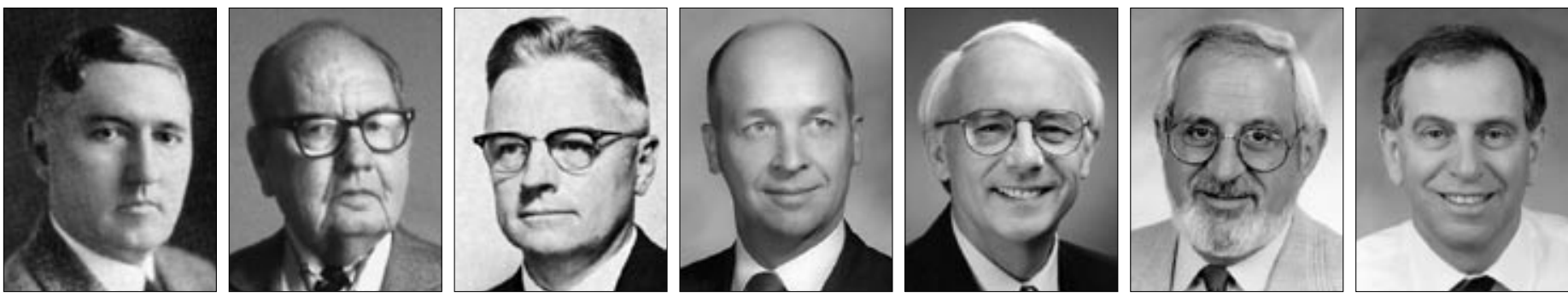

Figure 9. Chiefs of pediatrics at Baylor University Medical Center: Drs. Hugh Leslie Moore, Robert L. Moore, Floyd Norman, Percy E. Luecke, Jr., Ronald J. Hogg, Robert J. Kramer, and Jonathan M. Whitfield.

Dr. Percy E. Luecke, Jr., 1970 to 1987; Dr. Ronald J. Hogg, 1987 to 1990; Dr. Robert J. Kramer, 1990 to 1995; and Dr. Jonathan M. Whitfield, 1995 to present (Figure 9). The first 6 chiefs were physicians in private practice who assumed the additional duties of clinical chiefs during their tenures. In 1995, Dr. Jonathan M. Whitfield, the aforementioned director of neonatology, was named acting chief and, in 1996, full-time chief of pediatrics.

1. Levinson A. Pioneers of Pediatrics. New York: Froben Press, 1927.

2. Castiglioni A. A History of Medicine, 2nd ed. Krumbhaar EB, trans. New York: Knopf, 1947:855-860.
3. Garrison FH. An Introduction to the History of Medicine, with Medical Chronology, Suggestions for Study and Bibliographic Data, 4th ed. Philadelphia: Saunders, 1968:634.

4. Henderson L. Baylor University Medical Center: Yesterday, Today, and Tomorrow. Waco, Tex: Baylor University Press, 1978.

5. Children's Medical Center of Dallas. In The Handbook of Texas Online. Available at http://www.tsha.utexas.edu/handbook/online/articles/view/CC/ sbc3.html; accessed October 30, 2003.

6. James PW. Fifty Years of Baylor University Hospital. Dallas: Baylor University Hospital, 1953. 